\title{
Flutuação populacional de cigarrinhas-das-pastagens na Região Oeste do Paraná
}

\author{
Population dynamics of spittlebugs in the Western \\ Region of Paraná State
}

\author{
Tiago Rodrigo Lohmann ${ }^{1 *}$; Vanda Pietrowski; Dayanne Fabrício Bressan ${ }^{3}$
}

\begin{abstract}
Resumo
As cigarrinha-das-pastagens são consideradas as mais importantes pragas em pastagens tropicais. Os danos ocasionados por estes insetos diminuem a produção das pastagens. O objetivo deste trabalho foi estudar a flutuação populacional de Notozulia entreriana, no período de junho de 2007 a junho de 2008, e a correlação com os fatores meteorológicos/ambientais (precipitação pluviométrica, temperatura, radiação solar diária e altura da pastagem). Para tanto, amostraram-se três áreas de pastagem no município de Marechal Cândido Rondon-PR. Foram realizadas amostragens de adultos e ninfas. Também se determinaram quais as espécies de cigarrinhas-das-pastagens (Hemiptera: Cercopidae) ocorrem na região oeste do Estado do Paraná. A flutuação populacional de $N$. entreriana apresentou quatro picos durante o período favorável de desenvolvimento - primavera/verão. A radiação solar diária apresentou maior correlação com a dinâmica populacional. Por outro lado, precipitação pluviométrica, temperatura e altura da pastagem apresentaram pouca correlação com a dinâmica populacional. A espécie que ocorreu com maior abundância foi $N$. entreriana, representando $88,4 \%$ do total de insetos coletados na região oeste do Paraná.
\end{abstract}

Palavras-chave: Cercopídeos, radiação solar diária, dinâmica populacional, Cynodon dactylon. Rhynchospora sp

\begin{abstract}
The spittlebugs are considered the most important pests in tropical pastures. The damages caused by these insects decrease the production of pastures. The objective this work was to study the population dynamics of Notozulia entreriana, from June 2007 to June 2008, and the correlation with meteorological and environmental factors (rainfall, temperature, daily solar radiation and pasture height). Therefore, sampled were made in three areas of grassland in the municipality of Marechal Cândido RondonPR. Sampling of adults and nymphs was made. Also we determined which species of spittlebugs (Hemiptera: Cercopidae) occur in the western region of Paraná State. The population fluctuation of $N$. entreriana showed four peaks during the period of favorable development - spring / summer. The daily solar radiation had a higher correlation with the population. Rainfall, temperature and pasture height had little correlation with the population dynamics. The species that occurred with greater abundance was $N$. entreriana, representing $88.4 \%$ of the total insects collected in western of Paraná State.
\end{abstract}

Key words: Cercopids, daily solar radiation, population dynamics, Cynodon dactylon, Rhynchospora sp.

\footnotetext{
${ }^{1}$ Pós-graduando em Agronomia-Entomologia Agrícola pela Universidade Estadual Paulista 'Júlio de Mesquita Filho', UNESP. E-mail: lohmann tiago@hotmail.com

${ }^{2}$ Prof. Adjunto do Curso de Agronomia, Universidade Estadual do Oeste, UNIOESTE, Centro de Ciências Agrárias. E-mail: vandapietrowski@gmail.com

${ }^{3}$ Pós-graduanda em Agronomia-Produção Vegetal pela Universidade Tecnológica Federal do Paraná, UFTPR. E-mail: daybressan@ yahoo.com.br

* Autor para correspondência
} 


\section{Introdução}

A cigarrinha-das-pastagens Notozulia entreriana (Berg, 1879) é uma das principais pragas em pastagens da América Tropical (VALÉRIO; JELLER; PEIXER, 1997). São insetos que quando em altas populações reduzem o crescimento, a produção e a qualidade das gramíneas forrageiras susceptíveis (VALÉRIO, 2005). Adultos e ninfas de cigarrinha-das-pastagens se alimentam no xilema das plantas hospedeiras. Todavia, o principal dano ocasionado nas plantas é devido aos adultos que ao se alimentarem injetam compostos tóxicos através da saliva, que causam fitoxidade nas folhas. A atividade fotossintética é interrompida, causando lesões necróticas que se espalham longitudinalmente até o ápice das folhas. Como consequencia, a produção de massa seca, digestibilidade e qualidade da forragem é significativamente reduzida (VALÉRIO; WIENDL; NAKANO, 1988; HOLMANN; PECK, 2002).

Estima-se que 25 cigarrinhas por metro quadrado, em 10 dias, reduzam em $30 \%$ a produção do pasto atacado (ALMEIDA et al., 2000). De acordo com Bernardo et al. (2003), os danos provocados pelas cigarrinhas-das-pastagens variam para cada espécie de gramínea, sendo que os prejuízos econômicos podem ser consideráveis dependendo do local, condições climáticas e manejo. Algumas gramíneas possuem características morfofisiológicas que podem afetar negativamente o desenvolvimento do inseto (VALÉRIO; KOLLER, 1993; KOLLER; HONER, 1994; VALÉRIO, 2006).

Existem diversas espécies de cigarrinhas-daspastagens que ocorrem no Brasil, e várias são de importância econômica. Dependendo da região variam as espécies predominantes. As mais comuns são as do gênero Deois sp. e Notozulia entreriana (VALÉRIO, 2006).

O conhecimento da dinâmica populacional de cigarrinha-das-pastagens, juntamente com as espécies que ocorrem numa região, é de grande importância para a tomada de decisões quanto à época e o tipo de manejo a ser adotado no seu controle. Desta forma, o presente trabalho teve por finalidade estudar a flutuação populacional de $N$. entreriana e sua relação com as condições meteorológicas, e verificar quais espécies ocorrem na região oeste do Paraná.

\section{Material e Métodos}

O experimento foi conduzido de junho de 2007 a junho de 2008, em três áreas de pastagens, no município de Marechal Cândido Rondon - PR. Os dados de precipitação, temperatura média diária e radiação solar diária foram obtidos junto ao Instituto Nacional de Meteorologia - INMET (Estação Automática de Marechal Cândido Rondon).

O clima da região, segundo a classificação de Köppen, é subtropical, com temperatura média no mês mais frio inferior a $18^{\circ} \mathrm{C}$ (mesotérmico) e temperatura média no mês mais quente acima de $22^{\circ} \mathrm{C}$, com verões quentes, geadas pouco freqüentes e tendência de concentração das chuvas nos meses de verão, contudo sem estação seca definida. O município de Marechal Cândido Rondon apresenta altitude de 410 metros, latitude $24^{\circ} 33^{\prime} 40^{\prime \prime} \mathrm{S}$ e longitude $54^{\circ} 04^{\prime} 00^{\prime \prime} \mathrm{W}$.

Para o estudo da flutuação populacional de $N$. entreriana, amostraram-se três áreas de pastagem, duas cultivadas com Tifton 85 (Cynodon dactylon) (Pastagem 1 e 2) e uma com Capimestrela (Rhynchospora sp.) (Pastagem 3), com aproximadamente 5 ha cada e entre 7 e 9 anos de implantação.

Foram realizadas amostragens quinzenais, totalizando 23 amostras. Empregou-se dois métodos de coleta, um para adultos e outro para ninfas. O método empregado para adultos foi o de rede entomológica, com arco de $40 \mathrm{~cm}$ de diâmetro. Foram realizadas dez amostragens ao acaso com a rede entomológica, descrevendo uma trajetória aleatória dentro da área de pastagem entre os pontos de amostragens. Cada amostragem consistiu em dez passadas da rede rente às plantas. 
Os insetos coletados foram acondicionados em sacos plásticos, devidamente identificados e encaminhados ao laboratório de entomologia da UNIOESTE (Universidade Estadual do Oeste do Paraná), Campus de Marechal Cândido Rondon, onde se realizou a quantificação e separação por sexo das cigarrinhas-das-pastagens.

Para a quantificação das ninfas, utilizou-se um quadrado de $25 \times 25 \mathrm{~cm}$, tomando-se, ao acaso, dez pontos bem distribuídos na área, e ao redor de cada ponto jogando-se, também ao acaso, duas vezes o quadrado, totalizando vinte pontos amostrais por área. Em seguida, contou-se as ninfas presentes dentro do quadrado, normalmente localizadas nas raízes superficiais ou na parte basal das plantas (NILAKHE, 1982). As ninfas foram separadas conforme seu estágio de desenvolvimento em pequenas $\left(1^{\circ}\right.$ e $2^{\circ}$ instares $)$, médias $\left(3^{\circ}\right.$ e $4^{\circ}$ instares) e grandes ( $5^{\circ}$ instar). Em cada ponto amostral, mediu-se a altura da pastagem para posteriormente correlacionar com a quantidade de ninfas encontradas. As correlações de Spearman, entre altura da pastagem e as populações de ninfas de $N$. entreriana foram calculadas com o auxílio do programa BioEstat 5.0 e para tal foram considerados apenas os dados obtidos no período favorável ao desenvolvimento das cigarrinhas, da segunda quinzena de outubro de 2007 a segunda quinzena de março de 2008.

Os dados coletados foram correlacionados com as condições meteorológicas (Temperatura média diária $-{ }^{\circ} \mathrm{C}$; Precipitação média diária - mm; e Radiação solar diária - MJ.m-2 $\cdot$ dia $^{-2}$ ) com auxílio do programa BioEstat 5.0.

A coleta de cigarrinhas-das-pastagens, para o estudo das espécies que ocorrem na região oeste do Paraná, foi realizada em seis municípios da região -
Marechal Cândido Rondon, Toledo, Santa Helena, Maripá, Nova Santa Rosa e Pato Bragado - em diversas áreas de pastagem, perfazendo um total de 12, 11, 10, 6, 7 e 4 áreas amostradas por município, respectivamente.

A amostragem foi realizada com auxílio de rede entomológica. Em cada área de pastagem foram amostrados cinco pontos aleatórios, sendo que cada ponto consistiu em vinte passadas da rede sobre a pastagem. Os insetos coletados foram acondicionados em sacos plásticos e levados ao laboratório de entomologia da UNIOESTE para serem triados. A identificação das espécies foi confirmada pelo pesquisador, especialista em cercopídeos, Dr. Gervásio Silva Carvalho, professor na Pontifícia Universidade Católica de Porto Alegre - RS.

\section{Resultados e Discussão}

Coletou-se um total de 1235 ninfas e 5804 adultos durante o período de amostragens, considerando as três áreas de pastagens. Na média das três áreas, observa-se a ocorrência de quatro picos populacionais, tanto para adultos como para ninfas, sendo que para ambos, o segundo pico foi o maior (Figura1). A ocorrência dos picos de ninfas antecede os de adultos como é de se esperar conforme trabalhos de outros autores para cigarrinha-daspastagens (DOMINGUES; SANTOS, 1975; CASTRO; MORALES; PECK, 2005).

O desenvolvimento das gerações de $N$. entreriana ocorreu durante o período de maior precipitação pluviométrica, maiores temperaturas médias diárias (acima de $20^{\circ} \mathrm{C}$ ) e maiores valores de radiação solar diária, de outubro de 2007 a abril de 2008 (Figuras 2 e 3). 


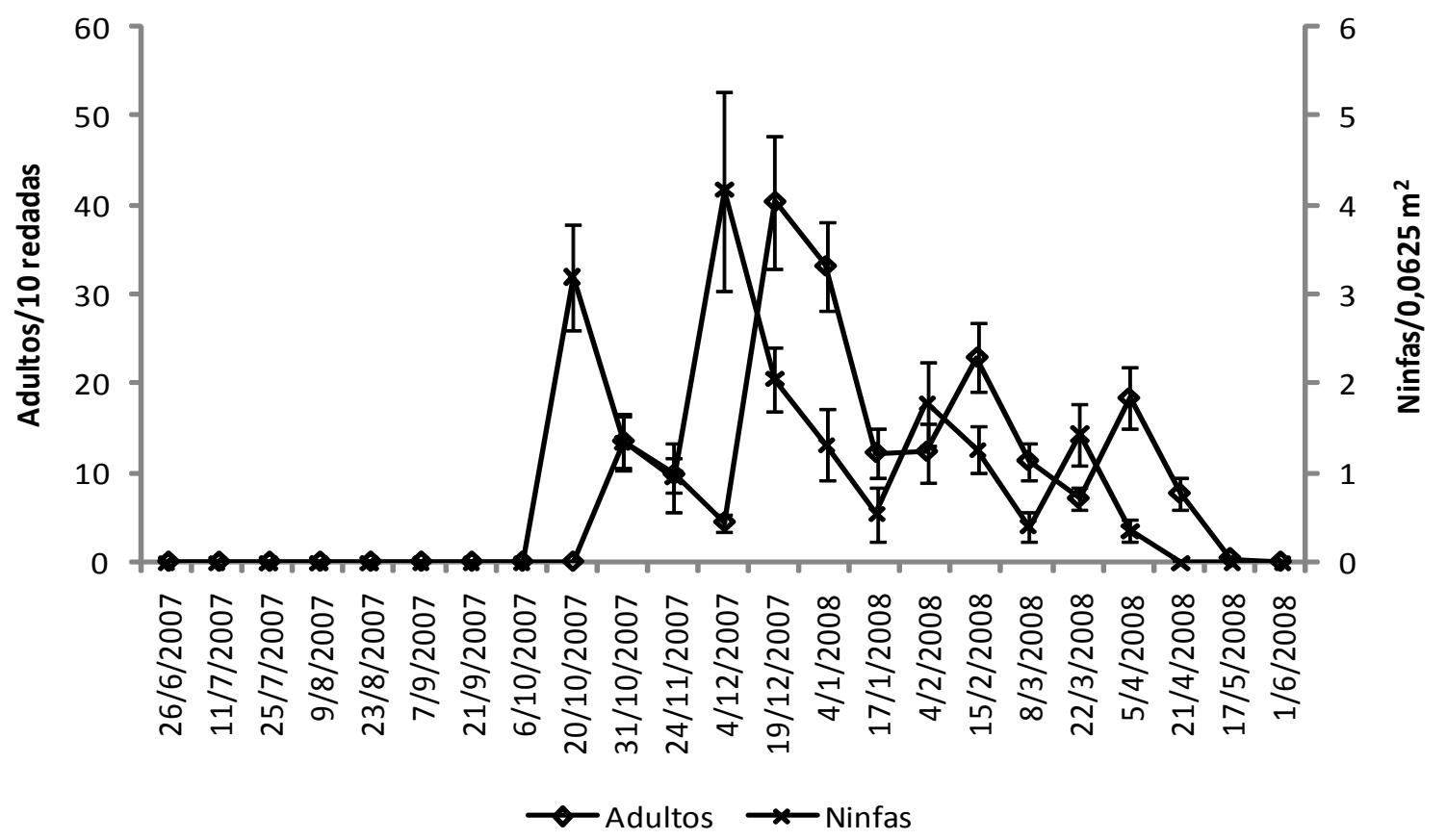

Figura 1. Flutuação populacional de ninfas e adultos de Notozulia entreriana, considerando a média das três propriedades amostradas, no período de junho de 2007 a junho de 2008, em pastagens do município de Marechal Cândido Rondon, PR.

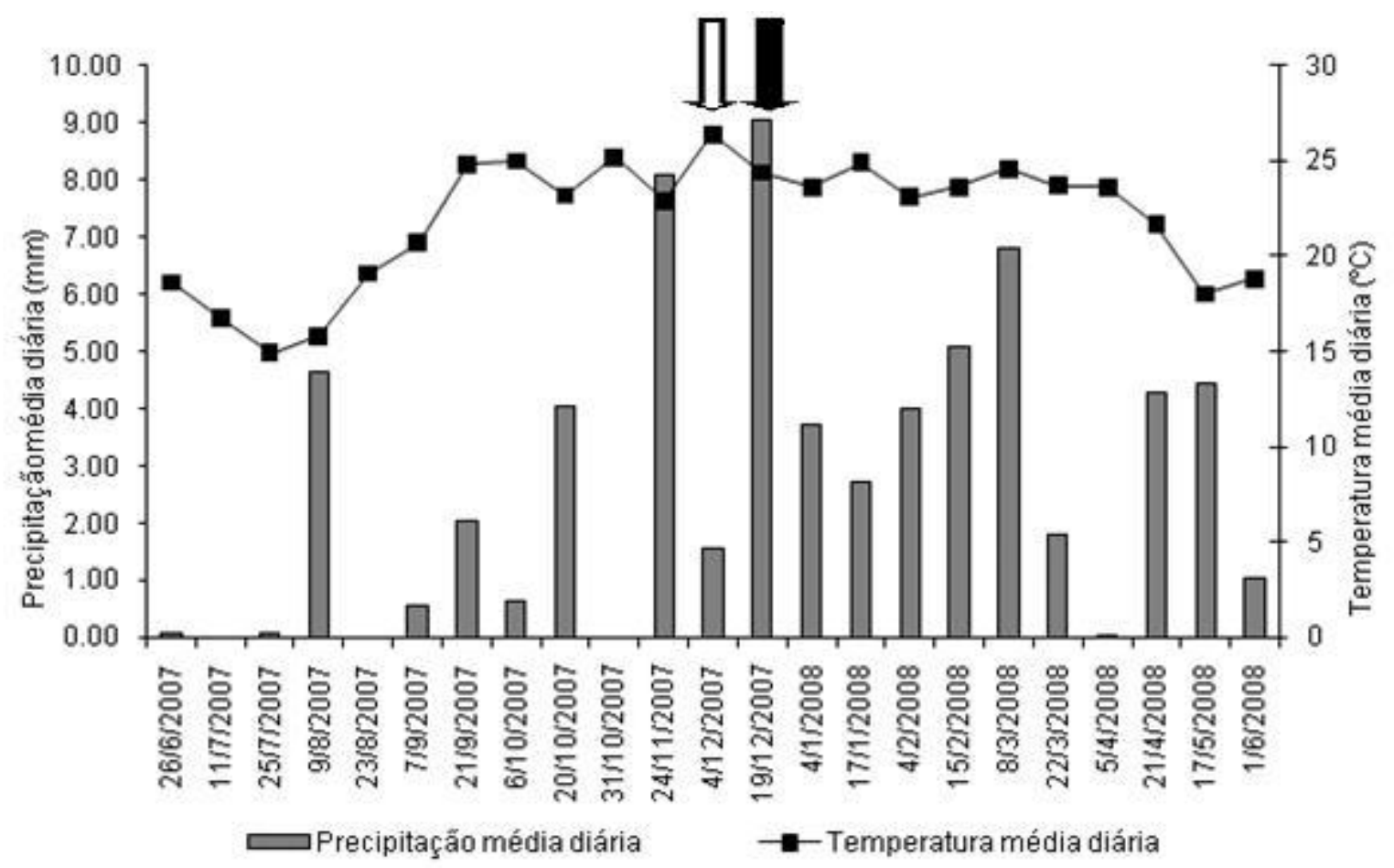

Figura 2. Dados de temperatura e precipitação médias diárias, no período de junho de 2007 a junho de 2008, no município de Marechal Cândido Rondon, PR. As setas vazia e cheia indicam, respectivamente, o maior pico populacional de ninfas e adultos.

Fonte: Instituto Nacional de Meteorologia - INMET. 


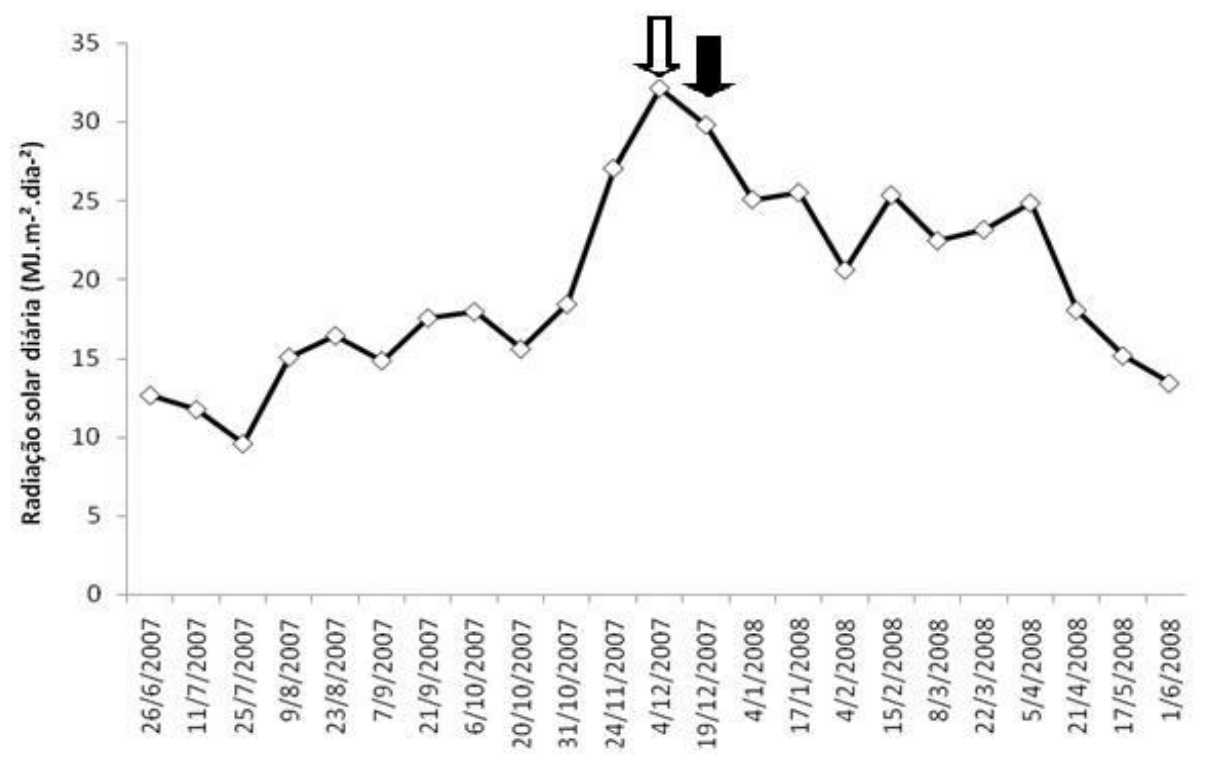

Figura 3. Dados de radiação solar diária, no período de junho de 2007 a junho de 2008, no município de Marechal Cândido Rondon, PR. As setas vazia e cheia indicam, respectivamente, o maior pico populacional de ninfas e adultos. Fonte: Instituto Nacional de Meteorologia - INMET.

O surgimento das ninfas esteve diretamente ligado à ocorrência das primeiras chuvas em setembro e outubro, após um período de estiagem e frio, no qual a população persistiu na forma de ovos diapáusicos em virtude das condições meteorológicas desfavoráveis. O mesmo fenômeno foi observado por Domingues e Santos (1975) no estado do Espírito Santo e Lyra Netto et al. (1989) para o estado de Pernambuco.

A separação das ninfas conforme seu estágio de desenvolvimento, mostrou um percentual igual para ninfas pequenas e médias (36\%) e menor para ninfas grandes $(28 \%)$. Esses percentuais sugerem que ao longo do desenvolvimento das ninfas há mortalidade, que pode ser devido a fatores ambientais ou biológicos, resultando num menor número de ninfas maiores, comparado ao número inicial de indivíduos. A separação por sexo dos adultos mostrou a ocorrência de um maior percentual de machos (63\%) em comparação às fêmeas (37\%), conforme os dados da (Tabela 1). Esses resultados são semelhantes aos obtidos por Castro, Morales e Peck (2005) para Zulia carbonaria na Colômbia.

Tabela 1. Número total de ninfas (pequenas, médias e grandes) e adultos (machos e fêmeas), e relação macho:fêmea das três áreas de pastagem no município de Marechal Cândido Rondon, PR, no período de junho de 2007 a junho de 2008.

\begin{tabular}{ccccccccccc}
\hline \multirow{2}{*}{ Pastagem } & \multicolumn{4}{c}{ Ninfas } & & \multicolumn{3}{c}{ Adultos } & Proporção \\
\cline { 2 - 4 } & Total & Pequena & Média & Grande & & Total & Machos & Fêmeas & M:F \\
\hline C. dactylon (1) & 176 & 66 & 51 & 59 & & 1025 & 716 & 309 & $2,3: 1$ \\
C. dactylon (2) & 275 & 49 & 106 & 120 & & 1685 & 1216 & 469 & $2,6: 1$ \\
Rhynchospora sp.(3) & 784 & 328 & 289 & 167 & & 3104 & 1756 & 1348 & $1,3: 1$ \\
Total & 1235 & 443 & 446 & 346 & & 5814 & 3688 & 2126 & $1,7: 1$ \\
\hline
\end{tabular}


A pastagem formada por capim-estrela (Rhynchospora sp.) apresentou maior número de cigarrinhas, tanto de adultos como de ninfas, em relação às outras duas, formadas por Tifton 85 ( $C$. dactylon). Isso pode sugerir uma maior preferência de $N$. entreriana por capim-estrela, ocasionando num melhor desenvolvimento dos insetos. Outra diferença entre as pastagens é refletida pela proporção macho: fêmea, sendo que a formada por capim-estrela (Rhynchospora $\mathrm{sp}$ ) apresenta a maior proporção de fêmeas. Devido a isso, provavelmente houve maior quantidade de postura, tendo como conseqüência maior crescimento populacional.

A correlação de Spearman entre ninfas e altura de pastagem foi significativa apenas para ninfas grandes, ou seja, quanto maior a altura da pastagem maior foi o número de ninfas grandes encontradas (Tabela 2). Tal fato pode ser um indicativo de que ninfas grandes sobrevivem mais quando protegidas da radiação solar e de inimigos naturais em um microambiente com maior altura de pastagem.

Tabela 2. Coeficiente de correlação de Spearman (rs) e probabilidade (p) entre fatores meteorológicos/ambientais e população de Notozulia entreriana, considerando a média das três áreas de pastagem no município de Marechal Cândido Rondon-PR, no período de junho de 2007 a junho de 2008.

\begin{tabular}{|c|c|c|c|c|c|c|c|c|}
\hline & \multicolumn{2}{|c|}{ Altura pastagem } & \multicolumn{2}{|c|}{ Temperatura } & \multicolumn{2}{|c|}{$\begin{array}{l}\text { Precipitação } \\
\text { pluviométrica }\end{array}$} & \multicolumn{2}{|c|}{ Radiação Solar Diária } \\
\hline & rs & $\mathrm{p}$ & rs & $\mathrm{p}$ & rs & $\mathrm{p}$ & rs & $\mathrm{p}$ \\
\hline \multicolumn{9}{|l|}{ Ninfas } \\
\hline Pequenas & -0.04 & 0.8968 & $0.55^{* *}$ & 0.0068 & $0.45^{*}$ & 0.0307 & $0.79 * *$ & $<0.0001$ \\
\hline Médias & 0.01 & 0.9828 & $0.6^{* *}$ & 0.0025 & 0.21 & 0.3313 & $0.63 * *$ & 0.0013 \\
\hline Grandes & $0.74 * *$ & 0.0055 & $0.56^{* *}$ & 0.0052 & 0.37 & 0.0858 & $0.71 * *$ & 0.0002 \\
\hline Total & 0.24 & 0.4432 & $0.59 * *$ & 0.0031 & 0.33 & 0.1267 & $0.73 * *$ & $<0.0001$ \\
\hline \multicolumn{9}{|l|}{ Adultos } \\
\hline Machos & - & - & $0.51 *$ & 0.0133 & 0.38 & 0.0758 & $0.80 * *$ & $<0.0001$ \\
\hline Fêmeas & - & - & $0.42 *$ & 0.0483 & $0.49 *$ & 0.0163 & $0.84 * *$ & $<0.0001$ \\
\hline Total & - & - & $0.49^{*}$ & 0.0186 & 0.40 & 0.0603 & $0.80^{* *}$ & $<0.0001$ \\
\hline
\end{tabular}

*Correlação significativa ao nível de $\mathrm{p}<0,05$

**Correlação significativa ao nível de $\mathrm{p}<0,01$

A correlação com a temperatura foi significativa para todas as categorias de ninfas e adultos, sendo que os valores de correlação foram maiores para as ninfas quando comparadas com os adultos. Isso demonstra o fato que as populações de $N$. entreriana se desenvolvem no período com temperaturas médias diárias maiores, na primavera/verão, declinando no outono até desaparecer quando as condições meteorológicas são desfavoráveis, com temperaturas baixas.

A precipitação pluviométrica é um fator essencial para a retomada do desenvolvimento das populações de $N$. entreriana após passar por um período de condições desfavoráveis. A correlação de ninfas pequenas com a precipitação foi significativa, indicando que a chuva desencadeia o fim do período diapáusico da cigarrinha-das-pastagens, fazendo com que esses ovos eclodam. Mesmo durante o período favorável ao desenvolvimento há a ocorrência de veranicos, e novamente a chuva pode desencadear a eclosão de maior número de ovos, fazendo com que a correlação entre ninfas pequenas e a precipitação pluviométrica seja significativa.

O fator meteorológico que apresentou maior correlação com as populações de $N$. entreriana foi a radiação solar diária. Tanto para ninfas quanto 
para adultos, considerando todas as categorias, a correlação foi altamente significativa $(\mathrm{p}<0,0001)$. Os valores de correlação de Spearman variaram entre 0,63 e 0,84 indicando que houve alta correlação com este fator meteorológico.

Os dados referentes à coleta de cigarrinha-daspastagens em vários municípios da região oeste do Paraná estão representados na (Tabela 3). A espécie mais abundante foi Notozulia entreriana (Berg, 1879) representando $88,4 \%$ do total de indivíduos coletados. A segunda espécie em representação foi Deois (Deois) rubropicta Sakakibara, 1979 com 6,7\%, seguida por Deois (Acanthodeois) flavopicta (Stål, 1854), Deois (Deois) mourei Cavichioli \& Sakakibara, 1993 e Deois schach (Fabricius, 1787) com $3,3 \%, 1,5 \%$ e $0,1 \%$ do total de indivíduos coletados.

Tabela 3. Número total de indivíduos coletados (n) e percentual relativo entre as espécies de cigarrinhas-das-pastagens coletadas com rede entomológica em áreas de pastagem em diferentes municípios da região oeste do Paraná, nos meses de janeiro e fevereiro de 2008.

\begin{tabular}{|c|c|c|c|c|c|c|c|c|c|c|c|}
\hline & \multicolumn{2}{|c|}{ N. entreriana } & \multicolumn{2}{|c|}{ Deois rubropicta } & \multicolumn{2}{|c|}{ Deois mourei } & \multicolumn{2}{|c|}{ D. flavopicta } & \multicolumn{2}{|c|}{ Deois schach } & \multirow{2}{*}{ Total } \\
\hline & $\mathrm{n}$ & $\%$ & $\mathrm{n}$ & $\%$ & $\mathrm{n}$ & $\%$ & $\mathrm{n}$ & $\%$ & $\mathrm{n}$ & $\%$ & \\
\hline MCR & 930 & 69.5 & 278 & 20.8 & 75 & 5.6 & 55 & 4.1 & 0 & 0.0 & 1338 \\
\hline Toledo & 730 & 76.0 & 128 & 13.3 & 28 & 2.9 & 74 & 7.7 & 0 & 0.0 & 960 \\
\hline SH & 593 & 94.9 & 23 & 3.7 & 2 & 0.3 & 6 & 1.0 & 1 & 0.2 & 625 \\
\hline Maripá & 331 & 71.0 & 29 & 6.2 & 2 & 0.4 & 99 & 21 & 5 & 1.1 & 466 \\
\hline NSR & 3068 & 98.9 & 23 & 0.7 & 2 & 0.1 & 10 & 0.3 & 0 & 0.0 & 3103 \\
\hline PB & 790 & 99.1 & 7 & 0.9 & 0 & 0.0 & 0 & 0.0 & 0 & 0.0 & 797 \\
\hline TOTAL & 6442 & 88.4 & 488 & 6.7 & 109 & 1.5 & 244 & 3.3 & 6 & 0.1 & 7289 \\
\hline
\end{tabular}

MCR - Marechal Cândido Rondon

SH - Santa Helena

NSR - Nova Santa Rosa

PB - Pato Bragado

Esses resultados divergem dos observados por Bernardo et al. (2003), onde a espécie D. flavopicta foi predominante (entre 70 e $80 \%$ do total de cercopídeos coletados) em coletas realizadas em cinco municípios do Estado de Mato Grosso. Contrariamente ao que ocorreu no presente trabalho, os autores observaram que a espécie $N$. entreriana foi pouco representada e pôde ser constatada em apenas um dos municípios totalizando apenas $12 \%$ do número de cigarrinhas-das-pastagens coletadas.

\section{Conclusões}

A flutuação populacional de $N$. entreriana em pastagens está diretamente relacionada com as condições meteorológicas/ambientais. $\mathrm{O}$ ressurgimento da população após um período desfavorável está relacionado com o aumento da temperatura, da radiação solar diária e da precipitação pluviométrica. A espécie mais abundante na região oeste do Estado do Paraná foi N. entreriana (Berg, 1879).

\section{Agradecimentos}

Ao Prof. Dr. Gervásio Silva Carvalho pela identificação dos insetos.

\section{Referências}

ALMEIDA, J. E. M.; FILHO, A. B.; COSTA, V. A.; LEITE, L. G.; RAMIRO, Z. A.; RUSSOMANO, O. M. R.; GRUPPA, P. C.; CALIL, E. M. B. Manejo integrado de pragas e doenças das pastagens. São Paulo: Secretaria de Agricultura e Abastecimento, 2000. 50 p. 
BERNARDO, E. R. A.; ROCHA, V. F.; PUGA, O.; SILVA, R. A. Espécies de cigarrinhas-das-pastagens (Hemiptera: Cercopidae) no meio-norte do Mato Grosso. Ciência Rural, Santa Maria, v. 33, n. 2, p. 369-371, 2003.

CASTRO, U.; MORALES, A.; PECK, D. C. Dinámica poblacional y fenología del salivazo de los pastos Zulia carbonaria (Lallemand) (Homoptera: Cercopidae) en el valle geográfico del río Cauca, Colombia. Neotrop. Entomol., Londrina, v. 34, n. 3, p. 459-470, 2005.

DOMINGUES, F. M.; SANTOS, E. M. S. Estudo da biologia da cigarrinha das pastagens Zulia entreriana Berg, 1879, e sua curva populacional no Norte do Estado do Espírito Santo. Vitória: EMCAPA, 1975. 42 p. (Boletim técnico, n. 2).

HOLMANN, F.; PECK, D. C. Economic damage caused by spittlebugs (Homoptera: Cercopidae) in Colombia: a first approximation of impact on animal production in Brachiaria decumbens pastures. Neotrop. Entomol., Londrina, v. 31, n. 2, p. 275-284, 2002.

KOLLER, W. W.; HONER, M. R. Desenvolvimento e sobrevivência de ninfas de cigarrinhas-das-pastagens (Homoptera: Cercopidae) sobre plantas de Brachiaria decumbens com diferentes características morfológicas. An. Soc. Entomol. Brasil, Londrina, v. 23, n. 2, p. 163170, 1994.

LYRA NETTO, A. M. C.; ARAUJO, A. D.; WARUMBY, J. F.; MARQUES, I. M. R. Flutuação populacional da cigarrinha de pastagens Deios schach (Fabricius, 1787) (Homoptera: Cercopidae) em capim pangola (Digitaria decumbens) no estado de Pernambuco. An. Soc. Entomol. Brasil, Londrina, v. 18, n. 1, p. 33-37, 1989.

NILAKHE, S. Amostragem de ninfas de cigarrinhas em pastagens de Brachiaria decumbens Stapf. Campo Grande: Embrapa-CNPGC, 1982. 65 p. (Boletim de Pesquisa, n. 2).

VALÉRIO, J. R. Considerações sobre a morte de pastagens de Brachiaria brizantha cultivar Marandu em alguns Estados do Centro e Norte do Brasil - Enfoque entomológico. In: BARBOSA, R. A. (Ed.). Morte de pastos de braquiárias. Campo Grande: Embrapa Gado de Corte, 2006. p. 135-150.

. Insetos-praga em pastagens tropicais. Informe Agropecuário, Belo Horizonte, v. 26, n. 226, p. 98-110, 2005.

VALÉRIO, J. R., WIENDL, F. M.; NAKANO, O. Injeção de secreções salivares pelo adulto da cigarrinha Zulia entreriana (Berg, 1879) (Homoptera, Cercopidae) em Brachiaria decumbens Stapf. Rev. Brasil. Entomol., São Paulo, v. 32, n. 3/4, p. 487-491, 1988.

VALÉRIO, J. R.; JELLER, H.; PEIXER, J. Seleção de introduções do gênero Brachiaria (Griseb) resistentes à cigarrinha Zulia entreriana (Berg) (Homoptera: Cercopidae). An. Soc. Entomol. Brasil, Londrina, v. 26, n. 2, p. 383-387, 1997.

VALÉRIO, J. R.; KOLLER, W. W. Proposição para o manejo integrado das cigarrinhas-das-pastagens. Pasturas Tropicales, Cali, v. 15, n. 3, p. 10-16, 1993. 